\title{
Role of Dual Energy Contrast Enhanced Spectral Mammography in Differentiation between Benign and Malignant Breast Masses
}

\author{
MOHAMED H. EL-SHAFEY, M.D.*; EL-SHIAMAA Z.M. EL-SHAHAWY, M.D.*; \\ AMAL A. HASHISH, M.D.** and GHADA A. KHEDR, M.Sc.*** \\ The Department of Diagnostic Radiology, Faculty of Medicine* and The Department of General Surgery, Faculty of Medicine**, \\ Tanta University and The Department of Diagnostic Radiology, Benha Educational Hospital***
}

\begin{abstract}
Background: Dual Energy Contrast Enhanced Spectral Mammography (DE-CESM) is a new and advanced clinical application of full field (FFDM) and is easily implemented, fast, and reproducible, and breast doses are comparable to those of standard digital mammography, it might be useful for shifting expensive MRI to digital mammography.

Aim of Study: To evaluate the enhancing power of the Contrast-Enhanced Spectral Mammography (CESM) on breast lesions and its ability to differentiate malignant from benign masses.

Patients and Methods: A prospective study was carried on 20 patients referred to Radio-Diagnosis Department. At the Air Forces Hospital over 12 months for the evaluation of breast masses, all patients were examined by a dual energy contrast enhanced spectral mammography, a complementary B-mode ultrasound and a histopathological examination of all masses.
\end{abstract}

Results: The study included 8 benign (40\%) and 12 malignant $(60 \%)$ masses, $17 / 20(85 \%)$ of them were enhanced while $3 / 20(15 \%)$ were not enhanced. The enhanced masses were further subdivided into faint $\&$ avid enhancement as well as homogenous, heterogeneous \& ring enhancement. Contrast uptake was significantly more frequent by malignant masses ( $p$-value $<0.301)$. Irregular mass lesions with intense and heterogeneous enhancement patterns correlated with a malignant pathology ( $p$-value $\leq 0.004$ ) DE-CESM was $91.7 \%$ sensitive and $87.5 \%$ specific. The positive and negative likelihood ratios were 91.7 and 87.5 respectively.

Conclusion: Using CESM to assess the morphology and enhancement characteristics of breast lesions improves the ability of digital mammography to differentiate benign from malignant breast lesions.

Key Words: Contrast-Enhanced Spectral Mammography (CESM) - Breast lesions - Malignant and benign masses.

Correspondence to: Dr. Mohamed H. El-Shafey, The Department of Diagnostic Radiology, Faculty of Medicine, Tanta University

\section{Introduction}

DETECTION of malignant breast lesions at earlier stages and their accurate differentiation from benign lesions is essential to reduce the associated morbidity and mortality and increase the 5-years survival rate up to $95 \%$ [1]. Mammogram is the basic imaging modality for early diagnosis of breast cancer [2] .

The dual-energy contrast-enhanced spectral mammogram is a new, easy, fast and reproducible advanced clinical application of FFDM with comparable breast doses to those of the standard digital mammogram [3]. Its mechanism of action is based on the detection of the angiogenesis associated with malignant breast lesions via monitoring the uptake of the injected iodinated nonionic contrast material [4].

The application of the dual-energy CESM with US permits the diagnosis of malignant breast lesions with more accuracy and sensitivity than the application of mammography with US alone [3]. Such technique might allow digital mammography to replace the expensive MRI [5]. Using CESM to assess the morphology and enhancement characteristics of breast lesions improves the ability of digital mammography to differentiate benign from malignant breast lesions.

\section{Patients and Methods}

This prospective study included 20 female patients, inclusion criteria (any patient with breast mass) exclusion criteria (allergy to contrast media, pregnancy, patient with histopathologically proved malignant breast masses). 
Each patient had one unilateral breast mass, aged from 40-65 years, with the mean age is 53 years. They were referred to the radio diagnosis department of the Air Forces Hospital from December 2016 to December 2017. All participants were subjected to a full history taking, consent taking; dual energy contrast enhanced mammographic examination, a complementary Ultrasound, and histopathological examination.

DE-CESM examinations were performed with a current full-field digital mammography system using a flat panel detector with CsI absorber, field size $19 \times 23$, del pitch of $100 \mathrm{~mm}$, image matrix size 1,914 X 2,294 (Senographe DS), with some specific software and hardware adaptations for the acquisition and image processing. Since the low energy level used in the standard mammogram is not sufficient to visualize low concentrations of iodine, changing the $\mathrm{X}$-ray spectrum to deliver energies just above the K-edge of iodine (33.2 $\mathrm{keV}$ ) was required. This could be done through the addition of a copper filter specifically designed for CEDM, in addition to the usual molybdenum and rhodium filters used for the conventional mammography. Moreover, the conventionally used voltage range $(26-32 \mathrm{kVp})$ is replaced by a higher one $(45-49 \mathrm{kVp})$. The exposure durations for a $5 \mathrm{~cm}$ thick, $50 \%$ glandular breasts are around 1 second and 3 seconds for the low and high energy images, respectively.

A catheter was inserted into the antecubital vein of the arm on the other side of the breast being examined. The non-ionic contrast agent (Omnipaque 300$)$ dose $(1.5 \mathrm{ml} /$ body weight $)$ was then injected intravenously in a single shot at a rate of $3 \mathrm{ml} / \mathrm{s}$. Two minutes after the initiation of the injection, the healthy breast was compressed in an MLO view capturing a pair of low-and high-energy images. Four minutes after the initiation of the injection, the diseased breast was compressed in the $\mathrm{CC}$ position capturing a pair of low-and highenergy images. A combination of low-energy and high-energy images through a specific image processing was performed to produce two subtracted images with contrast agent uptake information (one in the MLO and one in the CC view). The areas which did not take the contrast agent were removed from the image via the weighted subtraction of the two images. In order to eliminate the possibility of movement artifacts and to maintain image details associated with the conventional mammography the compression was only applied after the contrast injection.

\section{Image analysis:}

The subtracted images assess the presence or absence of contrast enhancement either (enhancing or non-enhancing mass), assessment of the pattern of the enhancement (homogenous or heterogeneous), assessment of the echogenicity of the enhancement (faint or avid or ring enhancement), analyzing the low-energy images was necessary to detect non-enhancing suspicious clusters of micro calcifications, focal asymmetries and distorted parenchyma and to assess the morphology of masses including margins (ill-defined, welldefined or speculated) and shape (irregular, oval or rounded).

\section{B- Mode ultrasonography:}

Conventional US examination was conducted using an annular-array mechanical sector scanner with a frequency of $7.5 \mathrm{MHz}$, obtaining images via a digital US scanner. None of the participants reported any adverse effects after the examination.

\section{Imaging method:}

Patient position: The inner medial breast was scanned while the patient lying supine and the outer lateral breast was scanned while the patient placed in the contra-lateral oblique position with her arm elevated and a pillow placed under her shoulder.

\section{Technique:}

Sagittal and transverse planes were the basic scanning plans to obtain three diameters of the lesion and other planes where only added whenever necessary according to the long axis of the mass. Both axillas were evaluated for pathological lymph nodes. Lesions were examined to determine their shape (oval, round or irregular), margin (speculated, micro lobulated, circumscribed or indistinct), echotexture (anechoic, hypo echoic, isoechoic, or hyperechoic), acoustic transmission and the presence of calcifications.

\section{Histopathologic diagnoses:}

Histopathologic diagnosis of specimens was used as a reference standards whether a true cut needle biopsy which was obtained under the guidance of U/S using 14-to 18-gauge needle, Fine Needle Aspiration Cytology (FNAC) or surgical biopsy.

\section{Results}

This study was carried out on 20 female patients who presented clinically by a breast lump. All participants underwent DE-CESM examination, ultrasound examination which were correlated with 
their pathological findings. Lesions were considered of the benign (BI-RADS) category if their shape was ovoid, round or macro-lobulated, their margins were circumscribed and with an abrupt interface to the normal parenchyma. On the other hand, lesions were considered malignant if their shape was irregular, lacked circumscribed margins, with a thick echogenic halo, complex ehcotexture, posterior acoustic shadowing or combined pattern and demonstrate micro calcifications. Of the included 20 patients, $8 / 20(40 \%)$ had benign masses and $12 / 20(60 \%)$ had malignant masses.

Table (1): Low energy mammographic finding of the studied cases $(n=20)$.

\begin{tabular}{lll}
\hline & $\mathrm{N}$ & $\%$ \\
\hline Mammographic findings shape: & & \\
(20 masses): & 5 & 25 \\
Rounded & 6 & 30 \\
Oval & 2 & 10 \\
Lobular & 7 & 35 \\
Irregular & & \\
Margins (20 masses): & 5 & 25 \\
Well-defined & 3 & 15 \\
Micro-lobulated & 7 & 35 \\
Ill-defined & 5 & 25 \\
Speculated & & \\
Calcifications (5 masses): & & \\
Micro calcifications & 4 & 20 \\
Macro calcification & 1 & 5 \\
\hline
\end{tabular}

Table (2): Describe DE-CEDM pattern \& degree.

\begin{tabular}{|c|c|c|c|c|c|c|}
\hline & \multicolumn{4}{|c|}{$\begin{array}{l}\text { Benign Malignant } \\
(\mathrm{n}=8) \quad(\mathrm{n}=12)\end{array}$} & \multirow{2}{*}{$x^{2}$} & \multirow{2}{*}{$\begin{array}{c}p- \\
\text { value }\end{array}$} \\
\hline & $\mathrm{N}$ & $\%$ & & $\%$ & & \\
\hline \multicolumn{7}{|c|}{ Enhancement patterns: } \\
\hline Homogeneous & 4 & 50 & 4 & 33.3 & 2.413 & 0.301 \\
\hline Heterogeneous & 2 & 25 & 7 & 58.3 & & \\
\hline Ring pattern & 2 & 25 & 1 & 8.3 & & \\
\hline \multicolumn{7}{|c|}{ Degree of enhancement: } \\
\hline Faint & 3 & 37.5 & 2 & 16.7 & 3.802 & 0.149 \\
\hline Intense & 2 & 25 & 7 & 58.3 & & \\
\hline No enhancement & 3 & 37.5 & 1 & 8.3 & & \\
\hline
\end{tabular}

We find that most of malignant masses showed avid enhancement on digital subtracted images, irregular shaped, speculated margin with similar features on ultrasound examination \& confirmed by hisopathological examination, while most of benign masses in our study showed regular shape , circumscribed margin with faint or no enhancement \& also similar features on ultrasound \&confirmed by histopathology as shown in the previous tables.
Table (3): Descriptor criteria by ultrasound of studied 20 female patients with breast masses.

\begin{tabular}{|c|c|c|c|c|c|c|}
\hline & \multicolumn{4}{|c|}{$\begin{array}{c}\text { Malignant Benign } \\
(\mathrm{n}=12) \quad(\mathrm{n}=8)\end{array}$} & \multirow[t]{2}{*}{$x^{2}$} & \multirow{2}{*}{$\begin{array}{c}p- \\
\text { value }\end{array}$} \\
\hline & $\mathrm{N}$ & $\%$ & $\mathrm{~N}$ & $\%$ & & \\
\hline \multicolumn{7}{|l|}{ Shape: } \\
\hline - Oval & 3 & 25 & 5 & 62.5 & 7.192 & $0.027 *$ \\
\hline - Rounded & 2 & 16.7 & 3 & 37.5 & & \\
\hline - Irregular & 7 & 58.3 & 0 & 0 & & \\
\hline \multicolumn{7}{|l|}{ Margins: } \\
\hline - Well-defined & 1 & 8.3 & 6 & 75 & 10.321 & $0.016^{*}$ \\
\hline - Ill-defined & 4 & 33.3 & 1 & 12.5 & & \\
\hline - Speculated & 5 & 41.7 & 0 & 0 & & \\
\hline - Micro-lobulated & 2 & 16.7 & 1 & 12.5 & & \\
\hline \multicolumn{7}{|l|}{ Acoustic transmission: } \\
\hline - Posterior shadowing & 9 & 75 & 0 & 0 & 11.632 & $0.003 *$ \\
\hline - Edge shadowing & 3 & 25 & 4 & 50 & & \\
\hline - Posterior enhancement & 0 & 0 & 3 & 37.5 & & \\
\hline \multicolumn{7}{|l|}{ Echogensity: } \\
\hline • Hypoechoic & 12 & 100 & 5 & 62.5 & 5.293 & $0.021 *$ \\
\hline - Hyperechoic & 0 & 0 & 0 & 0 & & \\
\hline - Anechoic & 0 & 0 & 3 & 37.5 & & \\
\hline \multicolumn{7}{|l|}{ Echo-texture: } \\
\hline • Homogenous & 2 & 16.7 & 6 & 75 & 6.812 & $0.009 *$ \\
\hline - Heterogenous & 10 & 83.3 & 2 & 25 & & \\
\hline \multicolumn{7}{|l|}{ Calcifications: } \\
\hline - Micro-calcifications & 5 & 41.7 & 0 & 0 & 8.001 & $0.005^{*}$ \\
\hline - Macro-calcification & 0 & 0 & 3 & 37.5 & & \\
\hline
\end{tabular}

Table (4): Histopathological classification of our study cases $(\mathrm{n}=20)$ histopathology.

\begin{tabular}{llc}
\hline & $\mathrm{N}$ & $\%$ \\
\hline A- Benign breast lesions $(n=8):$ & & \\
Fibro adenoma & 4 & 20 \\
Simple cysts & 2 & 10 \\
Complicated cyst & 1 & 5 \\
Lipoma & 1 & 5 \\
B- Malignant breast lesions ( $n=12):$ & & \\
Infiltrating ductal carcinoma (IDC) & 6 & 30 \\
Infiltrating lobular carcinoma (ILC) & 4 & 20 \\
Medullary carcinoma & 2 & 10 \\
\hline
\end{tabular}

Table (5): Showing sensitivity \& specificity.

\begin{tabular}{lcccc}
\hline Sensitivity & Specificity & PPV & NPV & Accuracy \\
\hline 91.7 & 87.5 & 91.7 & 87.5 & 90 \\
\hline
\end{tabular}


Pathological diagnosis: Invasive lobular carcinoma

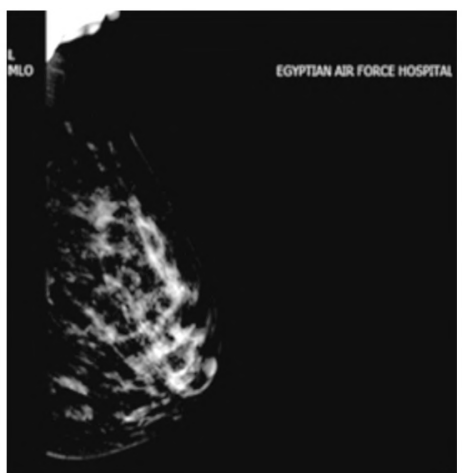

(A)

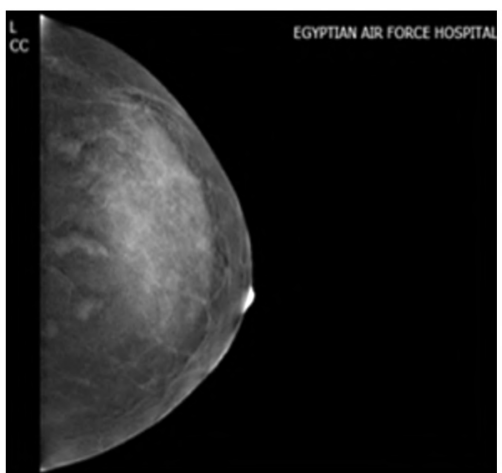

(B)

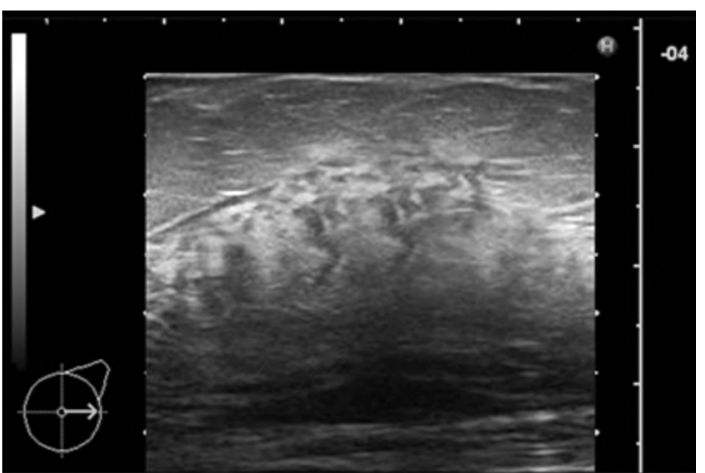

(C)

Fig. (1): 54 years old woman presenting with left breast stiffness \& mass associated with nipple discharge. (A) CC. low energy mammography of left breast showing ACR II with no evident opacity could be seen. (B) CC. Digital subtracted mammography of left breast Showing an ill-defined retro areolar diffuse opacity with faint enhancement. (C) B. mode ultrasound of the left breast B-mode U/S finding (C) Showing an ill-defined heterogeneous retro areolar non mass lesion BIRAD 4.

Pathological diagnosis: Invasive duct carcinoma

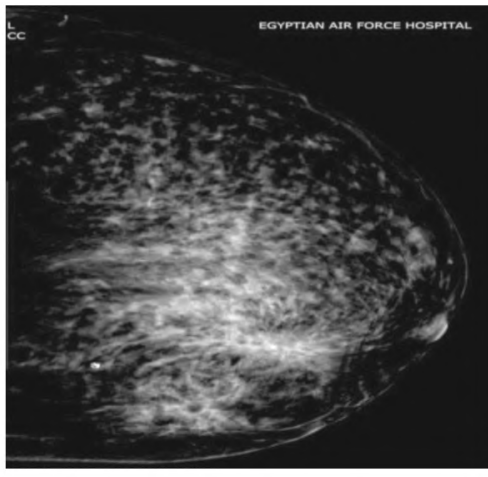

(A)

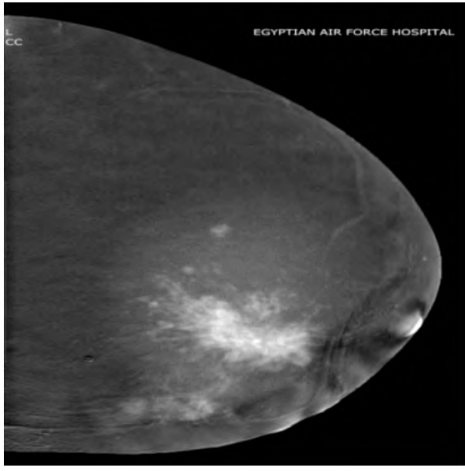

(B)

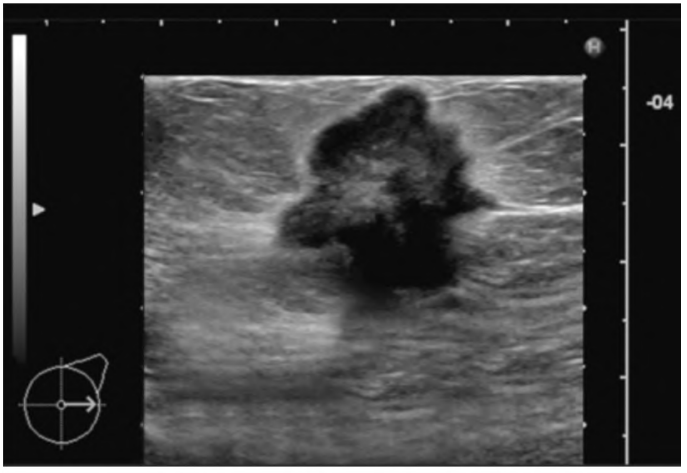

(C)

Fig. (2): 47 years old woman. Presenting with left breast mass. (A) CC low energy mammography of left breast showing ACR III with an indistinct irregular shaped speculated opacity seen at the lower inner quadrant. (B) CC digital subtracted mammography of left breast showing an ill-defined speculated opacity showing heterogeneous avid enhancement seen at lower inner quadrant with another adjacent faint enhanced opacity seen. (C) B. mode ultrasound showing left breast mass showing an irregular shaped hypo echoic soft tissue speculated mass lesion seen at approximately 5 o'clock BIRAD 5.

Pathological diagnosis: Showed fibro adenoma

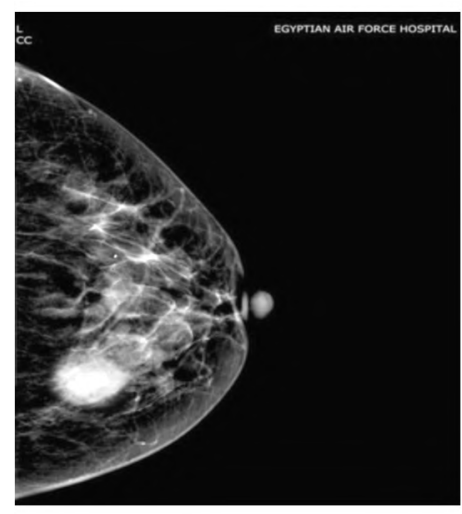

(A)

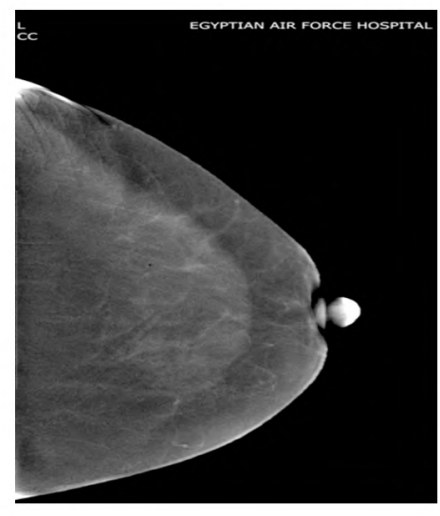

(B)

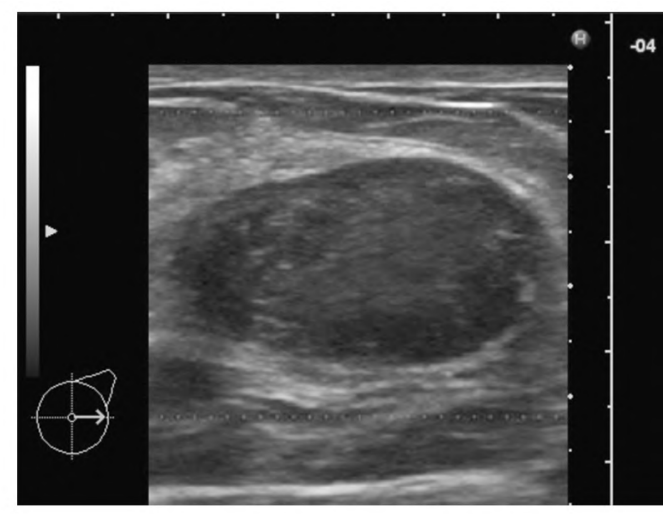

(C)

Fig. (3): 66 years old woman. presenting with left breast mass. (A) CC low energy mammography of the left breast. Showing ACR II with an oval shaped well defined regular outlined opacity seen at the upper inner quadrant BIRD3, (B) CC Digital subtracted mammography of the left breast showing no abnormal enhancement pattern. (C) B-mode ultrasound of the left breast. Showing an oval shaped hypo-echoic soft tissue lesion seen at approximately 11 o'clock BIRADS3. 
Pathological diagnosis: Invasive duct carcinoma

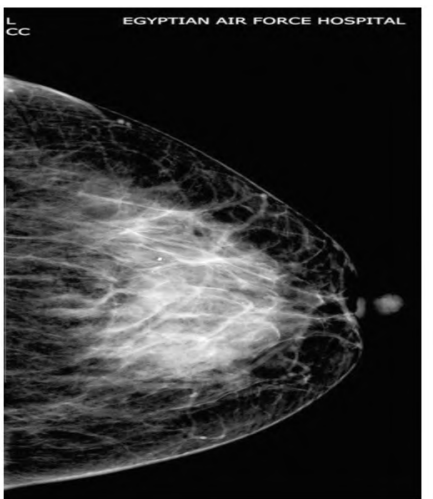

(A)

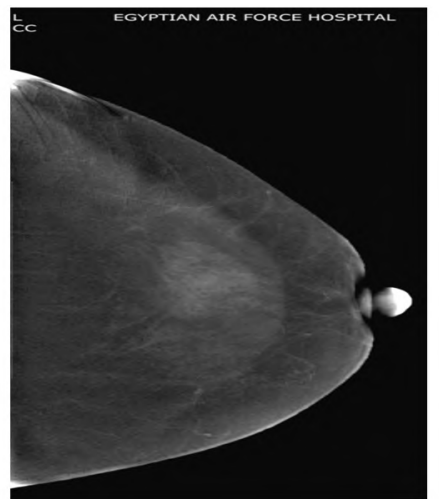

(B)

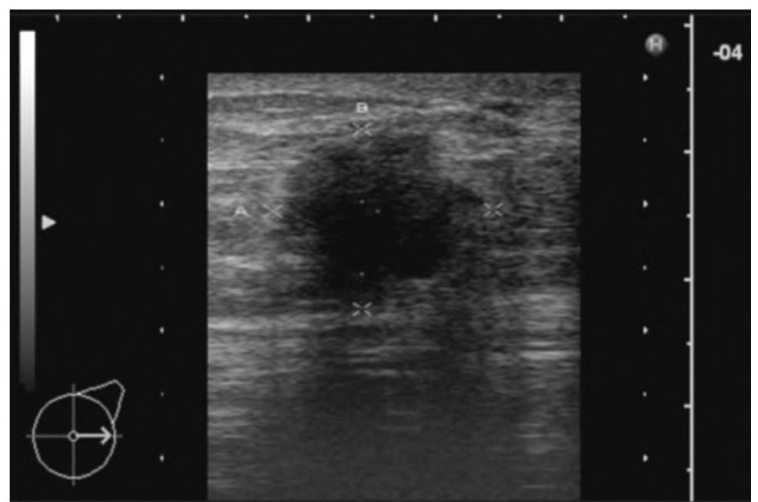

(C)

Fig. (4): 55 years old woman. presenting with left breast mass. (A) CC low energy mammography of the left breast showing ACR III with no evident opacity could be detected. (B) CC digital sub traced mammography of left breast showing an irregular shaped ill-defined homogenously, faint enhanced opacity seen at retro areolar region. (C) B. mode ultrasound of left breast mass. An ill-defined irregular shaped hypo echoic soft tissue mass with macro lobulated borders, with posterior shadowing, seen retro areolar area. BIRAD 5.

\section{Discussion}

In this study 20 female patients with breast masses (each patient with one unilateral mass) were examined to evaluate the role of DE-CESM and ultrasound BI-RADS, classification into final assessment categories to detect the presence of malignancy and its contribution to patient management.

Lawrence et al., 1994 [6] stated that the incidence of invasive duct carcinoma was $70.8 \%$, and lobular carcinoma was $6.8 \%$. This is in agreement with the current study which reported an incidence of invasive duct carcinoma of (83.3\%) and invasive lobular carcinoma of $(16.6 \%)$.

Hong et al., 2005 [7] stated that the shape, margin and boundaries differentiated benign from malignant lesions with a statistical significance. This coincides with this study which demonstrated the benign features of breast mass including oval or round shape, circumscribed margins while the malignant features included irregular shape, micro lobulation, indistinctness, and speculated margins.

Macura et al., 2006 [8] stated that speculated margins demonstrated a 91\% Positive Predictive Value (PPV) for malignant lesions. Their finding is matching with the result of this study in which speculated margins were only associated with malignant lesions.

In 2001, Lewin et al., evaluated the value of using a dual-energy contrast digital mammography based on a weighted subtraction of two images; one below and the other above the $\mathrm{K}$ edge of iodine [9] the morphology enhancement characteristics of benign and malignant breast lesions on dual-energy CESM are still under investigation. The current study evaluated the enhancement characteristics and morphology descriptors of DE-CESM on breast lesions, their value in the differentiation of benign and malignant breast lesions and whether the absence of contrast uptake would be an exclusion of malignancy or not.

Jong et al., reported that $89 \%(8 / 9)$ of the invasive cancers and $42 \%(5 / 12)$ of the benign lesions were enhanced [10], while in the present study, non-enhanced malignant lesions $(1 / 12,8.3 \%)$ were significantly less than non-enhanced benign lesions $(3 / 8,37,5 \%)$ ( $p$-value 0.149$)$, such finding emphasize the necessity of biopsy when suspicious findings are encountered in mammogram or ultrasound [8]

Lewin et al., 2003 [11]. Conducted their study on 26 cases, 13 of them had invasive malignant lesions, 11 of them demonstrated avid enhancement, 1 enhanced faintly, and 1 enhanced moderately. This coincides with the current study which reported 9 patients with avid enhancement with (7/12) malignant lesions $(58.3 \%)$ and $(2 / 8)$ benign lesions (25\%), faint enhancement in 5 patients with $(2 / 12)$ malignant lesions $(16.7 \%) \&(3 / 8)$ benign lesions $(37.5 \%)$.

The internal enhancement patterns of mass lesions were categorized into heterogeneous, homogeneous and ring-pattern. Malignant lesions were characterized by a heterogeneous uptake of the contrast (<-0.001). This could be attributed to the micro vascular density which determines the heterogeneity of tumor enhancement [12]. This coincides with this study that shows the lesions 
were heterogeneously enhanced in 9 patients with $(7 / 12)$ patients were malignant $(58,7 \%)$ and $(2 / 8)$ patients were benign (25\%), homogenously enhanced in 8 patients with (4/12) lesions were malignant $(33.3 \%) \&(4 / 8)$ lesions were benign $(50 \%)$ while ring enhanced was detected in 3 patients with (2/8) lesions were benign (25\%) and (1/12) lesion malignant $(8.3 \%)$.

Schnall et al., 2006 [13] reported a high correlation between ring-like enhancement and cancer diagnosis on MRI examination (PPV, 84\%). MRI (T2 image) was superior to DE-CESM as it can effectively exclude abscess cavities and infected cysts [12]. Thus, ring enhancement was not considered a reliable indicator of the nature of mass lesions in this study.

In conclusion, the morphology descriptors of breast lesions on DE-DESM can effectively differentiate benign and malignant breast lesions except for the ring pattern of contrast uptake which is not reliable in such matter.

Slantz et al., 2002 [14] did not approve the rule of echogenicity in the differentiation of solid breast masses due to the unavailability of a standardized definition of this parameter.

It is a fact that in comparison to the adjacent echogenic fibro glandular breast tissues, most tumors appear hypoechoic. In the study conducted by Moy, et al., 2002 [15] on 142 fibro adenomas and 149 breast cancer cases, 94 of fibro adenomas and $92 \%$ of invasive carcinomas were hypo-echoic. They reported that comparing the lesion echogenicity with that of the fat tissues instead of the fibro glandular tissue can yield more reliable data. This is in agreement with this study in which 12 malignant and 5 benign masses were hypoechoic which is not a definite differentiating sign between benign and malignant lesions.

Houssami et al., 2003 [16] stated that shadowing is a very important characteristic of malignancy. This is in agreement with the current study in which all malignant masses demonstrated a posterior shadowing.

Suspicious findings were divided into major and minor to distinguish category 4 and 5 lesions. Major suspicious findings included irregular shape, speculated margin, and micro calcifications. Minor suspicious findings included micro lobulated or angular margin, complex echogenicity, and posterior shadowing [17]. In the present study, BI-RADS category 4 and 5 were encountered in 8 and 3 lesions respectively.
Out of the 20 patients included in this study, 8 patients $(40 \%)$ were confirmed histopathologically to have benign breast lesions [ 15 (20\%) with fibro adenomas (the most common benign lesion), 2 (10\%) with simple cyst, 1 (5\%) with complicated cysts, $1(5 \%)$ with lipoma $1(2 \%)$ ]. 12 patients $(60 \%)$ were confirmed histopathologically to have malignant breast lesions [6 (30\%) with Infiltrating Ductal Carcinomas (IDC) (the most common malignant lesion), 4 (20\%) with infiltrating lobular carcinoma, 2 (10\%) with medullary carcinoma].

According to the present study, the conventional DE-CESM was $91.7 \%$ sensitive, $87.5 \%$ specific and $90 \%$ accurate. The PPV, and NPV were $91.7 \%$, and $87.5 \%$. These results correlate with the study done by Cheung YC1 et al., 2016 [18] DE-CESM was $90.9 \%$ sensitive, $83.78 \%$ specific, $86.4 \%$ accurate with a $76.92 \%$ positive predictive value and $93.94 \%$ negative predictive value.

To conclude, this study confirms that DE-CESM is an accurate diagnostic tool of breast malignancy and shows a clear potential of adding CEDM to improve the diagnosis of breast cancer. Also, DECESM is significantly more sensitive than MX alone and/or MX interpreted with US.

\section{References}

1- CHANG R.F.,CHEN C.J., CHIOU K.Y., et al.: Breast lesion classification using 3-D ultrasound. In: Suri J.S., Kathuria C., Chang R.F., Molinari F., et al. (eds). Advances in diagnostic \& therapeutic ultrasound imaging. 1 st edn. Artech House USA, pp. 142-64, 2008.

2- VAN DEN BIGGELAAR F.J., KESSELS A.G., VAN ENGELSHOVEN JIES M., et al.: Strategies for digital mammography interpretation in a clinical patent population. Int. J. Cncer, 125 (12): 2923-9, 2009.

3- DORMAIN C., FABIENNE T.H., DIEKMANN F., FALLENBERG E.M., et al.: Dual-energy contrast-enhanced digital mammography: Initial clinical results of a multireader, multicase study, 14: R94, 2012.

4- DORMAIN C. and BALLEYGUIER C.: Contrast enhanced digital mammography. In: Bick U, Diekmann F (eds). Digital mammography. 1 st edn. Springer-Verlag Berlin Heidelberg, pp. 1887-98, 2010.

5- DIEKMANN F., FREYER M., DIEKMANN S., et al.: Evaluation of contrast-enhanced digital mammography, Eur. L. Radiol., 78 (1): 112-21, 2011.

6- WAY L.W.: Current surgical diagnosis and treatment $10^{\text {th }}$ edition, University of California School of Medicin, $p$. 292-302, 1994.

7- HONG A.S., ROSEN E.L., SOO M.S. and BAKER J.A.: BI-RADS for sonography: Positive and negative predictive values of sonograsphic features. A.J.R. Am. J. Roentgenol., 184 (4): 1260-75, 2005. 
8- MACURA K.J., OUWERKERK R., JACOBS M.A. and BLUEMKE D.A.: Pattern of enhancement on breast MR images: Interpretation and imaging pitfalls. Radio. Graphics, 26: 1719-34, 2006.

9- DROMAIN C. and BALLEYGUIER C.: Contrastenhanced digital mammography. In: Bick U, Diekman F, editors. Digital mammography. Berlin, Heidelberg: Springer-Verlag, p. 187-98, 2010.

10- JONG R.A., YAFFE M.J., SKARPATHIOTAKIS M., SHUMAK R.S., DANJOUX N.M., GUNESEKARA A., et al.: Contrast-enhanced digital mammography: Initial clinical experience. Radiology, 228: 842-50, 2003.

11- LEWIN J.M., ISAACS P.K., VANCE V., et al.: Dualenergy contrast-enhanced digital subtraction mammography: Feasibility. Radiology, 229 (1): 261-8, 2003.

12- FALLENBERG E.M., DROMAIN C., DIEKMAN F., ENGELKEN F., KROHN M., SINGH J.M., et al.: Contrast-enhanced spectral mammography versus MRI: Initial resultsin the detection of breast cancer and assessment of tumor size. Eur. Radiol., 24 January (1): 256-64, 2014.

13- SCHNALL M.D., BLUME J., BLUEMKE D.A., DeANGELIS G.A., DeBRUHL N., HARMS S., et al.: Diagnostic architectural and dynamic features at breast MR imaging: Multicenterstudy. Radiology, 238 (1): 42-53, 2006.

14- SLANTS P.J., EDMISTER W.B., YEH E.D., et al.: Occult contralateral breast carcinoma inccidently detected. Breast Journal, 8 (3): 8-145, 2002.

15- MOY L., SLANETZ P.J., MOORE R., et al.: Specificity of mammography and US in the evaluation of palpable abnormality, retrospective view. Radiology, 225: 176-81, 2002.

16- HOUSSAMI N., IRWIG L., SIMPSON J.M., et al.: Sydney breast imaging study accuracy bstudy, comparative sensitivity and specificity of mammography and sonography in young women with symptoms. A.J.R., 180: 935-40, 2003.

17- EUN-KYUNG K., KO H.K., OH K., et al.: Clinical application of the birads final assessment to breast sonography in conjunction with mammography, American Journal of Roentgenology, Volume 190, Number 5, 1209$15,2008$.

18- CHEUNG Y.C.1,2, TSAI H.P.3,4, LO Y.F.3,4, UENG S.H.5, HUANG P.C.6 and CHEN S.C.3: Eur Radiol., Apr., 26 (4): 1082-9. Doi: 10.1007/s00330-015-3904-z. Epub 2015 Jul. 10, 2016. 


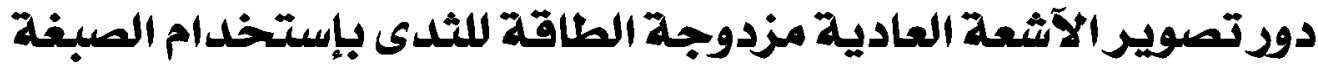

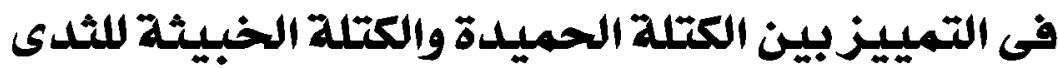

سرطان الثدى هو واحد من الآسباب الآكثر شيوعا للوفاة فى النساء. واحد من كل . . ا حالة وفاة فى جميع آنصاء العالم وقاحدة من كل

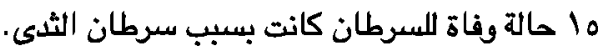

التصوير الشعاعى اللثى الرقمى هو الطريقة الوحيدة الذهبية القياسية لتصوير الثدى، ومع ذلك فإنه ليس آداة التمييز الآمثل بين الكتلة الحميدة للثىى والكتلة الضييثة اللثىى، وخاصة في حالات الثدى كثيف النسيج.

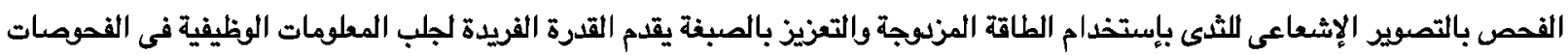

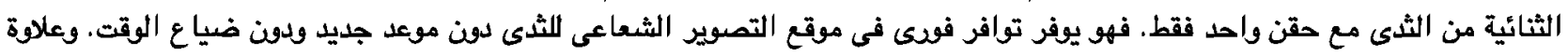

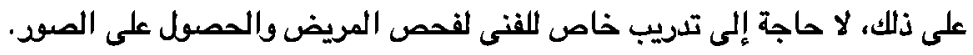

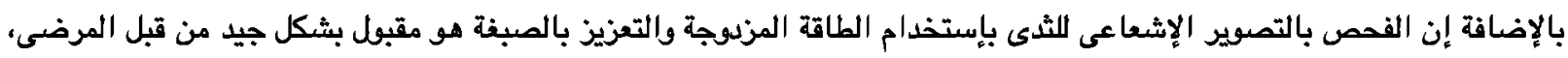

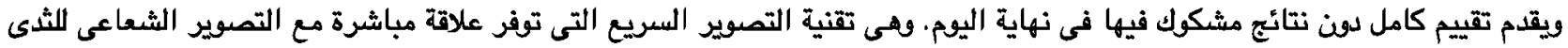

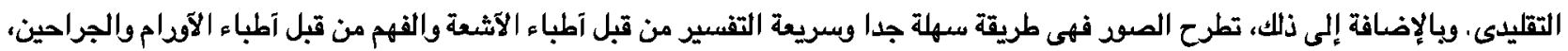

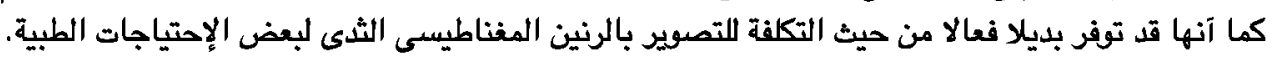

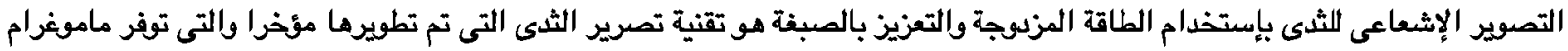

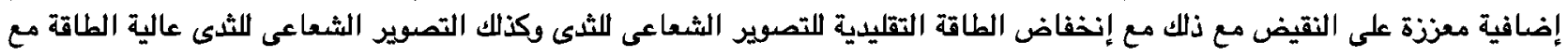

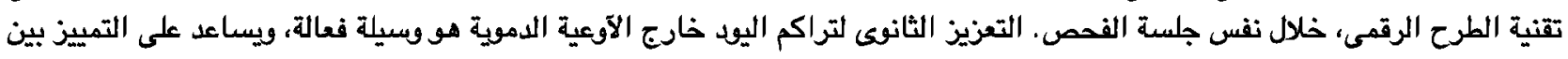
آودام الثىى السرطانية من تلك الحميدة عن طريق الكثف عن درجة ونمط تعزيز الصبغة. هذه التقنية يسهل الكثف وقياس حجم الآورام.

في لدراستنا قمنا بفحص .r حالة قدمت مع كتلة بالثدى، كتلة مع الآم بالثدى وكتلة مع نزول سائل من الحلمة.

وفقا لدراستنا الآودام غير منتظمة آو مفصصة الشكل، وسجلت تعزيز آقوى من الصبغة إعتبرت خبيثة، في حين إعتبرت الآودام مع شكل

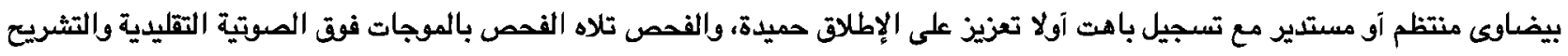
المرضى الذى آكد توقعاتنا بالتصوير الشعاعى الثنى.

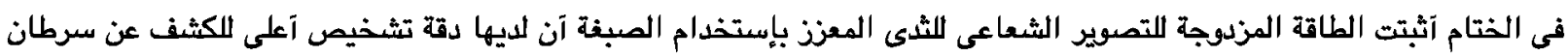

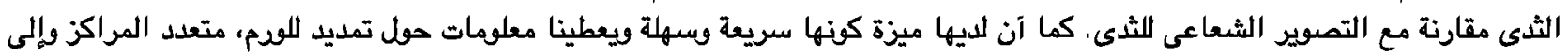

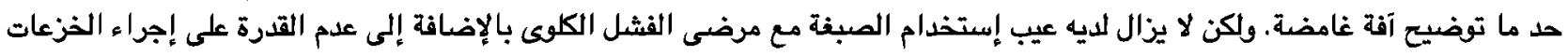

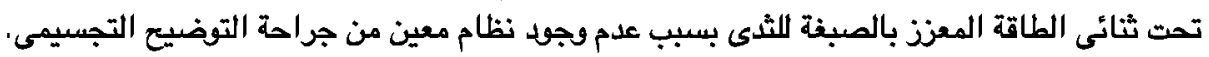

